\title{
Innovation and Risk-taking Propensity of Generation Y Students in South Africa
}

\author{
Habofanwe Andreas Koloba \\ Christopher May \\ School of Economic Sciences, North-West University, Vanderbijlpark, South Africa
}

\author{
Doi:10.5901/mjss.2014.v5n21p19
}

\begin{abstract}
Unemployment is a major problem in South Africa, especially among the Generation Y cohort. Many studies have been conducted not only in South Africa but across the world in an attempt to stem the tide of the continued rise in unemployment. Entrepreneurship, amongst other things, helps create jobs and generate wealth. The objective of this research study was to determine the perceptions of Generation Y students as regarding themselves as being innovative and risk-takers from an entrepreneurial perspective. Innovation and the willingness to take risk have been identified as important factors to become an entrepreneur. To collect the necessary data a convenience sampling method was employed where students were selected from two higher education institutions. A self-administered questionnaire was given to students to complete. The data were analysed using Principal Components Analysis to determine which items loaded on the two different constructs. T-tests were used to identify differences in responses from males and females as well as from designated racial groups. There were no significant differences found with regard to the innovative propensity construct between males and females, as well as between the two designated racial groups. While there were no significant differences the study showed that students had innovative characteristics. However, a number of significant differences were found with regard to the risk-taking propensity construct between the different groups as one designated racial group was more willing to take risks. It can be recommended that higher education institutions need to look at ways of how these entrepreneurial skills can be harnessed.
\end{abstract}

Keywords: Innovation; risk-taking; Generation Y; entrepreneurship

\section{Introduction}

The importance of entrepreneurship in contributing towards the development of the economic activities of countries is well established. Entrepreneurship creates jobs, generates wealth and contributes towards growth and development (Timmons \& Spinelli, 2004). The development of entrepreneurship is also viewed as one way to counter unemployment. South Africa, as a developing country, is also faced with the huge burden of unemployment. Many governments have gone the route to get individuals to engage in entrepreneurial activities, or self- employment, as an alternative to seeking employment.

South Africa, like any other country, is in need of individuals with the vital personal attitudes, aptitudes, values, perceptions, and ambitions to capitalise on opportunities to start their own businesses (Mueller \& Thomas, 2001). According to $\mathrm{Co}$ and Mitchell (2006), the only way for South Africa to effectively deal with unemployment and revitalise the economy is through the rediscovery of the entrepreneur who takes risks, breaks new grounds and be innovative. Sibanyoni (2011) states that South Africa has not done enough in developing entrepreneurship, and as a result the culture of entrepreneurship has been declining.

Entrepreneurship education is also important in nurturing entrepreneurship. However, very little has been done and there is a perception that research on entrepreneurship in South Africa is not rigorous (Co \& Mitchell, 2006). Ladzani and Van Vuuren (2002) conducted an analysis among service providers offering entrepreneurship training to small and medium enterprises in the Northern Province of South Africa and found that only 27 percent of the institutions provided significant entrepreneurship training. Entrepreneurship or the development thereof, is therefore very important in addressing some of the above problems.

\section{Literature Review}

The word entrepreneurship is derived from the French word entreprendre, meaning to commence, to chase opportunities and to accomplish needs and wants through innovation (Ndedi, 2009). The concept of entrepreneurship is both complex 
and controversial, as there is no agreement on the definition (Pretorius \& Van Vuuren, 2003; Longernecker, Moore \& Petty, 2003; Koh, 1996). Despite entrepreneurship enjoying admiration from the research community as a field of study, it remains poorly defined and its interpretation lacks coherence (Ma \& Tan, 2006). This lack of consensus has compelled many scholars and researchers to contextualise the definition of entrepreneurship. Despite the lack of consensus, researchers have continued to make an effort to define entrepreneurship. Ma and Tan (2006: 704) define entrepreneurship as "a particular type of mind-set, a unique way of looking at the world, a creative kind of adventure, and the ultimate instrument toward self-realisation and fulfilment". Furthermore, they suggest that at the heart of entrepreneurship lies in the wish to achieve, the zeal to create, the longing for free will, the drive for independence, and the embodiment of entrepreneurial visions and dreams through determined hard work, calculated risk-taking, continuous innovation and an undying perseverance.

Gürol and Atsan (2006) describe entrepreneurial activity for developed economies as a means of revitalising stagnated economies and in coping with unemployment problems by providing new job opportunities, while for developing economies it is seen as a system of economic progress, job creation and social change. Shastri, Kumar and Ali (2009) describe an entrepreneur as an individual or group of individuals who tries to create something new, who organises production and undertakes risk involved in the establishment and operation of a business enterprise. It is important to note that no single trait or characteristic defines the entrepreneur, nor does it allow one to predict entrepreneurial behaviour (Mueller \& Thomas, 2001).

There is agreement among scholars that entrepreneurs distinguish themselves from the rest by some of the common characteristics they have. The commonly cited characteristics of entrepreneurs from different studies on entrepreneurship are innovativeness, need for achievement, locus of control, risk-taking propensity, tolerance for ambiguity and self-confidence (Gürol \& Atsan, 2006). Creativity, a need for independence, commitment and high energy levels are some of the many characteristics that are normally associated with entrepreneurs (Roodt, 2005). The importance of entrepreneurial characteristics to the success of a business is supported by findings in a study by Entrialgo, Fernández and Vázquez (2000) among different firms in Spain. The findings revealed that most entrepreneurial firms were managed by individuals with greater locus of control, higher need for achievement and a greater tolerance for ambiguity.

Entrepreneurs tend to act autonomously, are prepared to innovate, take risk and being proactive to market opportunities (Lumpkin \& Dess, 1996). Lumpkin and Dess (2001) state that innovation refers to a willingness to support creativity and experimentation in introducing new products or services, originality, research and development and technological leadership in developing new processes. Similarly, Gürol and Atsan (2006) note that innovation has a comprehensive definition which include to create new products or new quality, to create new methods of production, to get into a new market, to create a new source of supply or to create a new organisation. Krauss, Frese, Friedrich and Unger (2005) consider an innovative individual as having a positive mind-set towards new ideas regarding products, services, administration or technological processes.

The significance of innovation to the success of a business is supported by the findings of Zhao (2005) among six organisations in Australia. The aim was to understand the relation between entrepreneurs and innovation. The findings showed that entrepreneurs and innovation are positively related and the combination of the two is important to business success and sustainability. Mueller and Thomas (2001) state that there appears to be strong practical evidence to support the claim that entrepreneurs are more innovative compared to non-entrepreneurs.

Risk-taking means a tendency to take bold actions such as venturing into unknown new markets, committing a large portion of resources to ventures with uncertain outcomes, and/or borrowing heavily (Lumpkin \& Dess, 2001). The degree of risk-taking refers to the tendency of an individual to display risk-taking when confronted with risky situations (Gürol \& Atsan, 2006). Koh (1996) is of the view that a person's risk-taking propensity can be defined as his/her orientation towards taking chances in uncertain decision-making context. Nonetheless, Dess and Lumpkin (2005) are of the view that only cautiously managed risk is likely to lead to competitive advantages. Furthermore, they argue that actions taken without adequate care, research and planning may prove to be very costly. A study by Tan (2001) conducted among entrepreneurs and managers of state owned enterprises in China found that managers were less willing to make risky decisions compared to entrepreneurs. Similarly, Stewart and Roth (2001) analysed studies pertaining to risk tendency differences between entrepreneurs and managers. The results also indicated that risk tendency of entrepreneurs is greater than that of managers.

Hermansen-Kobulnicky and Moss (2004) conducted a study among pharmacy students in the United States to determine their entrepreneurial orientation. The results showed that being willing to take risks appeared to be a distinct dimension influencing students to become entrepreneurs. Furthermore, Naldi, Nordqvist, Sjöberg and Wilkund (2007) conducted a study among family and non-family SMEs in Sweden. The results of the study supported the proposition that 
risk-taking is a distinct dimension of entrepreneurial orientation.

Kroon, de Klerk and Dippenaar (2003) view young people with entrepreneurial interests as a major facet in shaping the entrepreneurial future of a country. For this reason, an understanding of their entrepreneurial aspirations, interests and intentions is essential. The youth can earn their living by supporting themselves and their families with the income they make from their entrepreneurial activities (Ndedi, 2009). Knowledge of the factors that is linked with entrepreneurial tendency can have practical importance, for example, it can be used as a career guidance tool for students or as a device for selection of entrants into an entrepreneurship curriculum (Koh, 1996). Mitchell (2004) advises that identifying the factors that encourage the individual to embark on an entrepreneurial career becomes significant in stimulating entrepreneurship.

However, there is no consensus among researchers regarding the exact years that define Generation Y. Hill (2004) is of the view that Generation $Y$ includes persons born between 1981 and 2004. On the other hand Zimmerer and Scaborough (2008) see this generation as comprising of persons born between 1982 and 1995, while Tremblay, Audet and Gasse (2009) maintain that they are born between 1978 and 1990. This study follows the definition proposed by Markert (2004), who indicates that Generation Y encompasses individuals born between 1986 and 2005. Encouraging about this generation is that it exhibit high levels of entrepreneurship awareness (Zimmerer \& Scaborough, 2008). Although the characteristics of Generation $Y$ are documented, very few studies have focused on Generation $Y$ entrepreneurs (Tremblay et al. 2009). Generation Y makes up a considerable pool of prospective future entrepreneurs that will likely play a leading role in business success (Trembly et al. 2009).

The literature review focused on innovation and risk-taking as some of the commonly cited dimensions of entrepreneurial orientation. In view of this, this study sought to understand the perceptions of Generations $Y$ students as regarding themselves as being innovative and being prepared to take risks.

\section{Research Methodology}

\subsection{Sample}

A convenience sampling method was used to select the students from two higher education institutions by getting permission to hand out the questionnaires during class time for students to complete. A total of 347 questionnaires were completed.

\subsection{Instrument and procedure}

The questionnaire was designed after taking question items from previous studies and adapting them to fit the South African environment. The items regarding innovation were derived from two studies. The first was by HermansenKobulnicky and Moss (2004) among pharmacy students in the United States. The second study was by Mueller and Thomas (2001) among third- and fourth-year students at 25 universities in 15 countries. The risk-taking component of the questionnaire was developed after adapting the questionnaire that was used in a study by Lee, Lim, Pathak, Chang and Li (2006) among university students in the United States, Korea, China and Fiji. Section A of the questionnaire had demographic questions relating to gender, age, designated group (race) and year of study. Section B of the questionnaire comprised of items investigating the innovation and risk-taking propensity of generation $Y$ students. The items on section B were scored on a five-point Likert type scale ranging from 1 (strongly disagree) to 5 (strongly agree). A pilot study was conducted to determine whether the students understood the questions. Content and face validity of the questionnaire were established by asking a number of experienced academics to review the questionnaire. The Statistical Package for Social Sciences (IBM SPSS 22) was used to analyse the data.

\section{Results}

\subsection{Demographics}

The gender distribution was as follows, 207 (59.7\%) were female and 140 (40.3\%) were male students. Majority of respondents were aged between 19 and 21, constituting 73.8\%. In terms of designated groups (race), Blacks constituted $79.5 \%$ and Whites constituted $17.6 \%$. In addition, 163 respondents (47\%) indicated that they are in their second year of study. A further 144 (41.5\%) indicated that they are in their third year and 40 (11.5\%) were postgraduate. 


\subsection{Factor analysis}

Principal Component Analysis was used to determine the loadings on the two factors. The items loaded on two factors and there were no cross loadings. The Kaiser-Meyer-Olkin (KMO) measure of sampling adequacy was used to test the amount of variance that could be explained by the factors (Brace, Kemp \& Snelgar, 2009). In terms of the KMO index, a value close to one indicates that patterns of relationship are close, and that reliable factors are yielded. The Bartlett's test was used to determine if the data were factorable.

Table 1: Eigenvalues for the Innovation Construct

Total variance explained

\begin{tabular}{|c|c|c|c|c|c|c|}
\hline \multirow{2}{*}{ Component } & \multicolumn{3}{|c|}{ Initial Eigenvalues } & \multicolumn{3}{c|}{ Extraction Sums of Squared Loadings } \\
\cline { 2 - 7 } & Total & \% of Variance & Cumulative \% & Total & \% of Variance & Cumulative \% \\
\hline 1 & 2.980 & 49.662 & 49.662 & 2.980 & 49.662 & 49.662 \\
2 & .895 & 14.922 & 64.584 & & & \\
3 & .684 & 11.401 & 75.984 & & & \\
4 & .641 & 10.678 & 86.663 & & & \\
5 & .447 & 7.448 & 94.110 & & & \\
6 & .353 & 5.890 & 100.00 & & & \\
\hline
\end{tabular}

Extraction Method: Principal Component Analysis.

Rotation method: Varimax with Kaiser Normalisation

The Bartlett method indicates that when the $p$-value is less than the 0.05 significant level, then factor analysis would be considered appropriate. For the innovation construct the Kaiser-Meyer-Olin (KMO) value was 0.795 and the Bartlett's test 0.000. The cumulative variance explained was 49.662 as indicated in Table 1.

Table 2: Rotated Component Matrix for the Innovation Construct

\begin{tabular}{|l|c|}
\hline \multirow{2}{*}{} & Component \\
\cline { 2 - 2 } & 1 \\
\hline I want to be known as an innovator among my colleagues & .789 \\
\hline I can imagine myself doing something innovative as a business person & .768 \\
\hline I believe I will one day have skills needed to develop a new business & .731 \\
\hline I can see myself starting something innovative in the work-place & .717 \\
\hline I prefer work that requires original thinking & .613 \\
\hline I like to experiment with various ways of doing the same thing & .585 \\
\hline
\end{tabular}

The scale of the six items had a Cronbach alpha value of 0.793 . The six items that loaded on the innovation are provided in Table 2. The item "I want to be an innovator among my colleagues" had the highest loading on the innovation construct.

For the risk-taking construct, the KMO value was 0.83 and the Bartlett's test was significant at 0.05 . The scale also had a Cronbach alpha value of 0.790 . The total cumulative variance explained was $49.153 \%$ - see Table 3 . The component matrix of the risk-taking construct is provided in Table 4 with fairly high loadings. The item "I would like to dedicate my life to establishing a new business even if my parents were strongly against it" had the highest loading on the risk-taking construct.

Table 3: Eigenvalues Associated with the Risk-taking Construct

Total variance explained

\begin{tabular}{|c|c|c|c|c|c|c|}
\hline \multirow{2}{*}{ Component } & \multicolumn{4}{|c|}{ Initial Eigenvalues } & \multicolumn{3}{|c|}{ Extraction Sums of Squared Loadings } \\
\cline { 2 - 7 } & Total & $\%$ of Variance & Cumulative \% & Total & $\%$ of Variance & Cumulative \% \\
\hline 1 & 2.949 & 49.153 & 49.153 & 2.949 & 48.153 & \\
2 & .811 & 13.520 & 62.673 & & & \\
3 & .750 & 12.506 & 75.179 & & & \\
4 & .578 & 9.629 & 84.808 & & & \\
5 & .513 & 8.554 & 93.262 & & & \\
6 & .398 & 6.638 & 100.00 & & & \\
\hline
\end{tabular}

Extraction Method: Principal Component Analysis.

Rotation method: Varimax with Kaiser Normalisation 
A t-test was used to determine whether any significant differences existed between the innovative propensity of males and females. The data collected indicated that no significant differences could be found between males and females, except for the statement: "I like to experiment with various ways of doing the same thing." with a $p$ value of 0.05 . On this item, females appeared to prefer experimenting with various ways of doing the same thing, more than their male counterparts do. This finding can be seen as suggesting that, on this item, females are more innovative than their male counterparts. A t-test was also used to determine whether there were any differences in terms of the innovative propensity between South African Black and White ethnic groups. No significant differences were found. With regard to the gender risk-taking propensity construct it was found that there were two that were significant at the 0.05 level and one item at the 0.10 level - see Table 5.

Table 4: Rotated Component Matrix for the Risk-taking Construct

\begin{tabular}{|l|c|}
\hline & Component \\
\cline { 2 - 2 } & 1 \\
\hline I would like to dedicate my life to establishing a new business even if my parents were strongly against it & .787 \\
\hline I am more interested in establishing my own business then getting a job & .765 \\
\hline Even if I launch a new business and fail many times, I will keep on trying until I succeed & .742 \\
\hline I want to launch a new business of my own before graduation & .681 \\
\hline I am confident that I can successfully launch a new business on my own & .631 \\
\hline If I launch a new business, I will like to expand it to all over the world & .577 \\
\hline
\end{tabular}

Table 5: Differences between Generation Y Males and Females Regarding their Risk-taking Propensity - $t$-test for Equality of Means

\begin{tabular}{|ll|c|c|c|}
\hline & & $\boldsymbol{t}$ & df & Sig. (2-tailed) \\
\hline I want to launch a new business of my own before & Equal variances assumed & -1.738 & 343 & $.083^{\star *}$ \\
graduation. & Equal variances not assumed & -1.723 & 287.514 & .086 \\
\hline I am confident that I can successfully launch a new & Equal variances assumed & -2.133 & 343 & $.034^{*}$ \\
business on my own. & Equal variances not assumed & -2.233 & 334.911 & .026 \\
\hline If I launch a new business, I will like to expand it to & Equal variances assumed & -.920 & 342 & .358 \\
all over the world. & Equal variances not assumed & -.926 & 303.711 & .355 \\
\hline I am more interested in establishing my own & Equal variances assumed & -2.983 & 342 & $.003^{\star}$ \\
business then getting a job. & Equal variances not assumed & -3.043 & 315.442 & .003 \\
\hline I would like to dedicate my life to establishing a new & Equal variances assumed & -1.005 & 342 & .316 \\
business even if my parents were strongly against it. & Equal variances not assumed & -1.005 & 296.557 & .316 \\
\hline Even if I launch a business and fail many times, I will & Equal variances assumed & -1.412 & 342 & .159 \\
keep on trying until I succeed. & Equal variances not assumed & -1.438 & 314.105 & .152 \\
\hline
\end{tabular}

* Significant <p 0.05

** Significant $<p 0.10$

In all these cases the mean values of males were greater than the females where significant differences were found indicating that males were more prepared to take risks. With regard to the Generation $Y$ ethnic group comparison, four significant differences were found - see Table 6.

Table 6: Differences between Generation Y Black and White South African Ethnic Groups Regarding their Risk-taking Propensity - $t$-test for Equality of Means

\begin{tabular}{|l|l|c|c|c|}
\hline & & \multicolumn{1}{|c|}{$\boldsymbol{t}$} & df & Sig. (2-tailed \\
\hline I want to launch a new business of my own before & Equal variances assumed & -3.763 & 343 & $.000^{*}$ \\
graduation. & Equal variances not assumed & -4.002 & 93.874 & .000 \\
\hline I am confident that I can successfully launch a new & Equal variances assumed & -1.011 & 343 & .313 \\
business on my own. & Equal variances not assumed & -1.332 & 131.202 & .185 \\
\hline If I launch a new business, I will like to expand it to & Equal variances assumed & -1.017 & 342 & .310 \\
all over the world. & Equal variances not assumed & -.964 & 83.399 & .338 \\
\hline I am more interested in establishing my own & Equal variances assumed & -2.133 & 342 & $.034^{*}$ \\
business then getting a job. & Equal variances not assumed & -2.175 & 89.606 & .032 \\
\hline
\end{tabular}




\begin{tabular}{|l|l|c|c|c|}
\hline & & \multicolumn{1}{|c|}{ df } & Sig. (2-tailed \\
\hline I would like to dedicate my life to establishing a new & Equal variances assumed & -2.115 & 342 & $.035^{\star}$ \\
business even if my parents were strongly against it. & Equal variances not assumed & -2.097 & 86.996 & .039 \\
\hline Even if I launch a new business and fail many times, & Equal variances assumed & -4.232 & 342 & $.000^{\star}$ \\
I will keep on trying until I succeed. & Equal variances not assumed & -4.048 & 84.030 & .000 \\
\hline
\end{tabular}

* Significant $<p 0.05$

The Black ethnic group was more prepared to take risks compared to the White ethnic group as the mean values of the Black ethnic group were greater than the White ethnic group on all the items where significant differences were found.

\section{Discussion and Limitations of the Study}

The results of this study indicated that Generation $Y$ students tend to be innovative and prepared to take risks as the mean values of all the responses were greater than the average of the 5-point Likert scales used in the questionnaire. There were no significant differences between Generation $Y$ males and females as well as the two different ethnic groups with regard to the propensity construct of innovation. However, with regard to the risk-taking propensity construct there were quite a number of significant differences. Males as well as the South African Black ethnic group tended to be more risk orientated. There is adequate evidence to support the view that entrepreneurship is important for the economy of a country, irrespective of the level of development. However, for an individual to become an entrepreneur he/she has to possess unique characteristics. There is also sufficient evidence to support the view that entrepreneurs are not born, but they can be made through education and training (Timmons \& Spinelli, 2004).

The study focused on Generation $Y$ students at two higher education institutions and their views do not necessarily represent that of the total student population in the country. There is therefore scope to investigate the Generation $Y$ students across all institutions of higher learning in South Africa. It is evident that many factors influence entrepreneurial behaviour and in this study only two factors were investigated, namely, the propensity of innovation and risk-taking. Therefore, the influence of other factors can further be investigated. Given the fact that respondents in this study view themselves as being innovative and risk-takers, it will be interesting to find out why so many young people do not start businesses.

\section{Conclusion}

The findings from this research study have revealed that Generation $Y$ considers themselves as being innovative and risk-takers. However, they need assistance in engaging in entrepreneurial activities. Programmes can also be put in place to identify individuals with the necessary entrepreneurial characteristics at an early stage to provide the necessary support to develop them into successful entrepreneurs. This calls for more action and less talk if the country wants to lessen the unemployment among this group. All the stakeholders, including government, need to take cognisance of the fact that urgent steps are needed to create a favourable environment for entrepreneurial activities to take place.

\section{References}

Brace, N., Kemp, R. \& Snelgar, R. (2009). SPSS for Psychologists. (4th ed.). New York: Palgrave McMillan.

Co, M. J. \& Mitchell, B. (2006). Entrepreneurship education in South Africa: a nationwide survey. Education and Training, 48(5), 348359.

Dess, G. G. \& Lumpkin, G. T. (2005). The role of entrepreneurial orientation in stimulating effective corporate entrepreneurship. Academy of Management Executive, 19(1), 147-156.

Entrialgo, M., Fernández, E. \& Vázquez, C. J. (2000). Characteristics of managers as determinants of entrepreneurial orientation: Some Spanish evidence. Enterprise and Innovation Management Studies, 1(2), 187-205.

Gürol, Y. \& Atsan, N. (2006). Entrepreneurship characteristics amongst university students: Some insights for entrepreneurship education and training in Turkey. Education and Training, 48(1), 25-38.

Hermansen-Kolbulnicky, C. J. \& Moss, C. L. (2004). Pharmacy student entrepreneurial orientation: a measure to identify potential pharmacist entrepreneurs. American Journal of Pharmaceutical Education, 68(5), 1-10.

Hill, K. S. (2004). Defy the decades with multigenerational teams. Nursing Management, 35(1), 32-35.

Koh, H. C. (1996). Testing hypotheses of entrepreneurial characteristics: A study of Hong Kong MBA students. Journal of Managerial Psychology, 11(3), 12-25.

Krauss, S. I., Frese, M., Friedrich, C. \& Unger, J. M. (2005). Entrepreneurship orientation: a psychological model of success among southern African small business owners. European Journal of Work and Organizational Psychology, 14(3), 315-344.

Kroon, J., De Klerk, S. \& Dippenaar, A. (2003). Developing the next generation of potential entrepreneurs: co-operation between schools 
and business. South African Journal of Education, 23(4), 319-322.

Ladzani, W. M. \& Van Vuuren, J. J. (2002). Entrepreneurship training for emerging SME's in South Africa, Journal of Small Business Management, 40(2), 154-161.

Lee, S. M., Lim, S. B., Pathak, R. D., Chang, D. \& Li, W. (2006). Influences on students attitudes toward entrepreneurship: a multicountry study. Entrepreneurship Management, 2(3), 351-366.

Longernecker, J. G., Moore, C. W. \& Petty, J. W. (2003). Small business management: an entrepreneurial emphasis. (12th ed.). Mason, Ohio: Thomson: South-Western.

Lumpkin, G. T. \& Dess, G. G. (1996). Clarifying the entrepreneurial orientation construct and linking it to performance. Academy of Management Review, 21(1), 135-172.

Lumpkin, G. T. \& Dess, G. G. (2001). Linking two dimensions of entrepreneurial orientation to firm performance: the moderating role of environment and industry life cycle. Journal Business Venturing, 16(5), 429-451.

Ma, H. \& Tan, J. (2006). Key components and implications of entrepreneurship: A 4-P framework. Journal of Business Venturing, 21(5), 704-725.

Markert, J. (2004). Demographics of age: Generational and cohort confusion. Journal of Current Issues and Research in Advertising, 26(2), 11-25.

Mitchell, B.C. (2004). Motives of entrepreneurs: A case of South Africa. Journal of Entrepreneurship, 13(2), 167-183.

Mueller, S. L. \& Thomas, A. S. (2001). Culture and entrepreneurial potential: a nine country study of locus of control and innovativeness. Journal of Business Venturing, 16(1), 51-75.

Naldi, L., Nordqvist, M., Sjöberg, K. \& Wilkund, J. (2007). Entrepreneurial orientation, risk-taking and performance in family firms. Family Business Review, 20(1), 33-47.

Ndedi, A. A. (2009). Entrepreneurship training and job creation in South Africa: Are tertiary institutions filling the gap? Journal of Contemporary Management, 6(1), 463-470.

Pretorius, M. \& Van Vuuren, J. (2003). Contribution of support and incentive programs to entrepreneurial orientation and start-up culture in South Africa, South African Journal of Economic and Management Sciences, 6(3), 514-528.

Roodt, J. (2005). Self-employment and the required skills. Human Science Research Council, Management Dynamics, 14(1), 18-33.

Shastri, R. J., Kumar, S. \& Ali, M. (2009). Entrepreneurship orientation among Indian professional students. Journal of Economics and International Finance, 1(3), 085-087.

Sibanyoni, M. (2011). SMMEs lose faith in finance houses. City Press, 27 November.

Stewart, W. H. \& Roth, P. L. (2001). Risk propensity differences between entrepreneurs and managers: a meta-analytic review. Journal of Applied Psychology, 86(1), 145-153.

Tan, J. (2001). Innovation and risk-taking in a transitional economy: a comparative study of Chinese managers and entrepreneurs. Journal of Business Venturing, 16(4), 359-376.

Timmons, J. A. \& Spinelli, S. (2004). New venture creation. Entrepreneurship for the 21st century. (6th ed.). Boston: McGraw Hill//rwin.

Tremblay, M., Audet, J. \& Gasse, Y. (2009). Aspiring entrepreneurs: The case of Generation Y. Southern Journal of Entrepreneurship. Papers and Proceedings of the Southern Academy of Entrepreneurship 2009 Annual Conference. Columbus. Georgia.

Zhao, F. (2005). Exploring the synergy between entrepreneurship and innovation. International Journal of Entrepreneurial Behaviour and Research, 11(1), 25-41.

Zimmerer, T. W. \& Scarborough, N. M. (2008). Essentials of entrepreneurship and small business management. (5th ed). New Jersey: Pearson Prentice Hall. 
